\title{
The Application of Traditional Cultural Elements in the Creative Design of Chinese Characters
}

\author{
Lei Wang ${ }^{1, *}$ \\ ${ }^{1}$ School of Design and Art, Xijing University, Xi'an, Shaanxi 710123, China \\ ${ }^{*}$ Corresponding author. Email: 13720521680@163.com
}

\begin{abstract}
Chinese nation has a long history, and the culture of the Chinese nation is extensive and profound. Chinese characters in Chinese traditional culture are the characters with the most national characteristics at this stage. As an intuitive form of visual expression, Chinese characters show its own unique and profound charm. In the shape design of Chinese characters, the designers load their own national feelings into the cultural creative design of Chinese characters, the forms of Chinese characters reflect a strong national element and national characteristic. Chinese characters, the unique form of Chinese nation, have many connections with other national cultures. It is precisely because of the profound background and cultural connotation of Chinese characters themselves, that when human beings see Chinese characters, they all have deep national pride and strong national pride.
\end{abstract}

Keywords: Chinese characters, Nationality, Fonts, Publicity media.

\section{INTRODUCTION}

The visual design art of Chinese characters needs Chinese traditional cultural elements to provide design ideas. It is suggested to further refine and analyze the national cultural symbols, carry forward and learn from the creation of Chinese character art, so as to create excellent creative Chinese characters.

Nowadays, many Chinese character cultural designers have different discussions on Chinese character design, but there are few conceptual contents of comprehensive comparison. The analysis of Chinese traditional elements can not only enrich modern text posters and text blackboard writing to a certain extent, but also enhance the design meaning of fonts. [6]

\section{HISTORICAL BACKGROUND OF CHINESE CHARACTERS}

At the beginning of human society, productivity was extremely low. In order to exchange ideas and transmit information, language was born. However, language would vanish in a flash. At the same time, language can neither be preserved nor transmitted to a distant place. For some information that needs to be retained and transmitted to a distant place, it is not possible to rely on the memory of human brain alone. Therefore, the original recording methods "keeping records by tying knots" and "keeping recording by carving wood" came into being. According to these legends, human beings know that primitive characters gradually formed and evolved in the long-term production practice. The characters can not be invented and created by anyone alone, but the product of the operation of the whole society. [1]

\section{CHINESE CHARACTER CONSTRUCTION AND FORMATION METHOD}

From the perspective of structure, Chinese characters can be divided into two categories: single character and composite character composed of two or more single characters. A Chinese character composed of a font formation component is a single character, and a Chinese character composed of more than two single characters is a composite character. The structure of Chinese characters mainly aims at the structure of composite character. Chinese character is a plane figure. If there is only one font formation component, there is no structural distribution. If two or more font 
formation components are combined together, how to arrange the position will be a problem.

\section{THE MEANING OF TRADITIONAL CULTURE}

Culture is a vague concept. Its core is all kinds of knowledge as spiritual products, and its essence is communication. Traditional culture is a kind of national culture which reflects national characteristics and styles and is the overall representation of various ideological cultures and ideological forms in the history of a nation. [2] Chinese traditional culture is the crystallization of Chinese civilization for thousands of years. In addition to the core content of Confucian culture, it also includes other cultural forms, such as Taoist culture, Buddhist culture and so on.

\section{THE INFLUENCE OF TRADITIONAL CULTURAL ELEMENTS ON THE CREATIVE DESIGN OF CHINESE CHARACTERS}

The "inherent cultural system" human beings often say in life is actually formed in the long-term production and life, and is the product of the development in the long-term historical process of a nation. After thousands of years of development, the culture of the Chinese nation has been handed down from generation to generation and has a certain stability. In the process of development, affected by various external environment and selfdevelopment factors, it has a specific connotation and occupies the leading position. Traditional culture includes both material form and spiritual aspect. Traditional culture shows its unique characteristics in the traditional values, lifestyle, regional customs and psychological features of the Chinese nation. Traditional culture is not only a nation's basic value orientation, but also affects a nation's unique way of life. To a great extent, it is a profound embodiment of national self-esteem and national pride.

Modern design has many aspects. As an important branch of modern art design, the basic design form of Chinese characters has great differences in different regions under the influence of social changes. In Japan, the neighboring country, there are quite a lot of designers specializing in font research and design. It can be predicted that Japan has invested a lot of energy in font design. At the same time, it can reflect that Japan attaches great importance to local culture. Many graphic elements can be clearly found on some publicity posters with its own characteristics and style in Japan, which are the expression forms of its national symbols. On the basis of using their own cultural characteristics, they fully reflect the cultural connotation on the font, so as to achieve the purpose of promoting culture. [3]

In the design of characters, it has become an effective consensus of all nationalities to fully highlight the meaning of national culture. A distinctive form of expression with nationalization is the common goal. In the shape design of Chinese characters, Chinese designers fully integrate the graphic symbols in traditional culture with the overall design of Chinese characters, which is in line with today's development trend and can directly affect the special expression charm of Chinese characters. By systematically understanding the unique artistic meaning of Chinese characters and deeply understanding the local national culture, designers can clearly realize the impact of the development of characters on the public. Designers should make full use of the charm of words to express a kind of information, which can express the superficial meaning of words, but also promote the development of national culture and make writing creativity have its own unique artistic appeal through the forms of artistic expression.

The development of the Chinese nation has thousands of years of history. Through continuous creation and accumulation, it has its own system. As a representative of the beauty of Oriental characters, the shape of the characters themselves has the following meanings:

- The unique charm of aesthetics

Chinese characters have their own system and form their own school in image expression.

- Various forms of expression

The Chinese character font of Chinese national culture is a summary of Chinese traditional culture. Chinese traditional culture has many forms of expression, and the creative Chinese characters designed have national vitality, national symbolism and national image appeal. 


\section{APPLICATION OF CHINESE TRADITIONAL NATIONAL CULTURE IN CHINESE CHARACTER CULTURAL CREATIVITY SUCH AS FONT POSTER DESIGN}

\subsection{The Embodiment of Integrating National Cultural Elements and Chinese Characters in Publicity Media}

Nationality refers to a group of people who are objectively distinguished from other groups in culture, language and history. It is a concept formed by studying the history of human evolution and race since modern times. Due to historical reasons, a country can have different nationalities, and a nation can live in different countries. The modern national concept can be a group of people distinguished by the country, or a group of people who have a common cultural concept without a common language and historical source. In modern times, the same nation can have different religious beliefs; the same nation can also have different historical origins; different nations can also use the same language; and different nationalities can also be integrated into new nationalities in the later stage. The word "Chinese nation" is a combination of the word "China" with a long history and the word "nation" introduced from the West since modern times. Liang Qichao, Yang Du and Zhang Taiyan were pioneers who used the word "Chinese nation" earlier. "Chinese nation" is a word commonly used, full of a sense of 5000 years of historical vicissitudes.

When human beings talk about the Chinese nation, the first things that come into mind are "descendants of the dragon" and "Chinese descendants". National cultural elements emphasize not similarity in shape, but the similarity in spirit. When designing, designers comprehensively use some basic concepts of geometry to deform, reorganize, integrate and refine the form of a Chinese character, and finally shape it into a new Chinese character, so as to realize the vision and understanding of the most primitive and essential nature. It is necessary to further analyze and explore the artistic conception of Chinese characters through several artistic elements.

\subsubsection{Ink Calligraphy Elements}

The obvious difference between Chinese calligraphy and other types of calligraphy is that
Chinese calligraphy takes Chinese characters as the inside information. Chinese calligraphy refers to the writing of Chinese characters and is the expression of Chinese character art. Calligraphy takes Chinese characters as the main means to show the unique artistic charm of Chinese calligraphy through the expression of artistic modeling. Chinese characters are an important part of Chinese calligraphy. Chinese calligraphy is produced in the long-term development of Chinese culture, and Chinese characters are the basic elements of Chinese culture. [4]

In the creative design of Chinese character culture, the design form of ink culture plays an important role in the artistic works of calligraphy. The conceptual integration of ink calligraphy and Chinese character design not only gives the traditional ink calligraphy a new meaning, but also makes Chinese character design have more means. In the posters of 2008 Olympic Games, the calligraphy and Chinese character graphics of "高" (high), "快" (fast), "强" (strong) and "搏" (stroke) are added to the sports form as the basic design elements. At the same time, it makes people associate with the sports spirit and create an artistic conception of being positive and carrying forward the sports spirit. This is a very high form of artistic expression and the display of artistic charm.

\subsubsection{Folk Paper-cutting Elements}

In China, paper-cutting has a broad mass base, blends in the social life of people of all ethnic groups, and is an important part of various folk activities. The profound expression of paper-cutting elements contains rich cultural and historical information, expresses the social recognition, moral concept, practical experience, life ideal and aesthetic taste of the general public, and has multiple social values such as cognition, education, expression, lyricism, entertainment and communication. " 福 " (happiness), as a representative character of Chinese nation, has its own unique meaning, and also has its own unique embodiment at the new year's moment and during festivals and holidays. The paper-cutting form of this word can be seen that the structure is complex and perfect, the shape changes are various, and different font shapes reflect different visual beauty and psychological feelings. The decoration of paper-cutting art can not only reflect the cultural concept and wisdom of the Chinese nation, but also reflect the aesthetic taste of the Chinese nation. 


\subsubsection{Seal-cutting Elements}

Ancient hieroglyphic seals are generally engraved with images of people and animals, which are broad, thick, simple, concise and vivid. There are many forms, such as pure picture, and picture with words. Today, most of them are from the Han Dynasty. Patterns and pictures were printed from the Warring States period to the Han and Wei Dynasties, with that of Han Dynasty as the most. The development of seal-cutting art has a long history, but it is this historical state that makes it have rich historical charm. The artistic analysis of seal-cutting should be carried out from the aspects of structure, tone and basic style. In order to realize the unity of form and spirit of art, it emphasizes the harmony and unity of the whole. The emblem of the Beijing Olympic Games is the profound embodiment of seal-cutting art. The emblem of Beijing Olympic Games is the combination of "京" (Beijing) and 文" (culture), reflecting the charm of sports.

\subsection{Problems in Chinese Font Design at the Present Stage}

In reality, designers only work behind closed doors. In the creativity of writing art, designers only care about their own development and do not learn from the advanced and reasonable experience of others. Foreign character art design started earlier, and with a long time of development, foreign character art design has become a school of its own. Their artistic expression is inspired by careful observation of some details in life. Moreover, it should be emphasized that they are very good at practicing some of their own ideas. They have achieved the concept of "art existing in life everywhere". In contrast, some designers in China are alone in the design room with a computer for simple design, and cannot realize the idea of burst of inspiration. [5]

They made blind imitation and plagiarism, and did not form their own characteristics. Some designers directly copy other people's works without their own innovation and artistic conception.

The details of workmanship are rough, and the picture has no beauty. In the detailed polishing of some works, designers did not strive for perfection, the overall aesthetic feeling was very poor, and the overall modelling characteristics were lacking.

\section{CONCLUSION}

In the cultural creativity of Chinese characters, the deep integration with traditional culture can further improve the ideological breadth and depth of creativity. By comprehensively analyzing the shape, structure and relevant contents of disassembly and reorganization of Chinese characters, and selecting some representative contents for analysis, it is concluded that the traditional cultural elements are indispensable cultural elements in the creative design of Chinese characters. Chinese traditional culture is broad and profound. It is in the communication with the outside world that human beings should fully learn from its purification and abandon some bad aspects. Under the trend of economic globalization, the creative design of Chinese characters has faced more challenges. At the same time, it is also an opportunity for comprehensive upgrading and a key node to achieve a historic leap. Human beings in China should bravely seize this opportunity, meet the challenge, excavate Chinese traditional culture and pay equal attention to inheritance and innovation.

\section{AUTHORS' CONTRIBUTIONS}

This paper is independently completed by Lei Wang.

\section{REFERENCES}

[1] David Juri. What is text design? [M]. Beijing: China Youth Publishing House. 2007. (in Chinese)

[2] Yang Yuefeng. Research on the Application of Deconstructed Chinese Characters in Modern Packaging Design [D]. Chongqing: Art College of Chongqing University. 2007. (in Chinese)

[3] Kohei Sugiura. Books in Asia - Text and Design [M]. Yang Jing, Li Jianhua Trans. Life-Reading·Xinzhi Sanlian Bookstore. 2006. (in Chinese)

[4] Liu Yuanman. Research on the Cultural Significance of Chinese Characters in Japan [M]. Beijing: Peking University Press. 2003. (in Chinese)

[5] Nan Hexi. The charm of words: Chinese characters in the eyes of a Japanese [M]. Wang Baoping Trans. Shanghai: Shanghai 
Ancient Books Publishing House. 2002. (in Chinese)

[6] Wang Ning. Ten Lectures on Chinese Characters and Chinese Culture [M]. Beijing: Life-Reading Xinzhi Sanlian Bookstore. 2018. (in Chinese) 